\title{
Representation of less-developed countries in Pharmacology journals: an online survey of corresponding authors
}

Dileep K Rohra

\begin{abstract}
Background: Scientists from less-developed countries (LDC) perceive that it is difficult to publish in international journals from their countries. This online survey was conducted with the primary aim of determining the opinion of corresponding authors of published papers in international Pharmacology journals regarding the difficulties in publications and their possible solutions.

Methods: The titles of all Pharmacology journals were retrieved from Pubmed. 131 journals were included in study. The latest issue of all journals was reviewed thoroughly. An online survey was conducted from the corresponding authors of the published papers who belonged to LDC.

Results: 584 out 1919 papers (30.4\%) originated from the LDC. 332 responses (response rate; 64.5\%) were received from the authors. Approximately 50\% the papers from LDC were published in journals with impact factor of less than 2. A weak negative correlation $(r=-0.236)$ was observed between journal impact factor and the percentage of publications emanating from LDC. A significant majority of the corresponding authors ( $n=254 ; 76.5 \%$ ) perceived that it is difficult to publish in good quality journals from their countries. According to their opinion, biased attitude of editors and reviewers (64.8\%) is the most important reason followed by the poor writing skills of the scientists from LDC (52.8\%). The authors thought that well-written manuscript (76.1\%), improvement in the quality of research (69.9\%) and multidisciplinary research (42.9\%) are important determinants that may improve the chances of publications.

Conclusions: The LDC are underrepresented in publications in Pharmacology journals. The corresponding authors of the published articles think that biased attitude of the editors as well as the reviewers of international journals and the poor writing skills of scientists are the major factors underlying the non-acceptance of their results. They also think that the improvement in the writing skills and quality of research will increase the chances of acceptance of their works in international journals.
\end{abstract}

\section{Background}

Publishing in prominent scientific journals provides better visibility and impact of research results at individual as well as institutional and national level. Scientists are under continuous pressure to publish in international journals in order to obtain rewards and promotions [1,2]. This also applies to scientists residing in less-developed (middle and low income) countries. Scientists from lessdeveloped countries (LDC) perceive that it is difficult to

Correspondence: drohra@alfaisal.edu

Department of Pharmacology, Alfaisal University, Riyadh, Kingdom of Saudi Arabia

\section{() Biomed Central}

get publications in reputable biomedical journals and the results of the studies in the fields of epidemiology [3], psychiatry [4], and cardiology [5] confirm the underrepresentation of LDC authors in the respective international journals. The conclusion of one survey indicates that researchers from LDC believe that the editorial bias against their works based on geographical location is a major reason for underrepresentation in publications [6].

In addition to quantity, the quality is increasingly recognized as a critical aspect while evaluating research. In the 1970s, some objective parameters were suggested as a means to evaluate quality of research $[7,8]$. Among these parameters, the impact factor (IF) of the journal is widely 
employed as a tool to judge the quality of scientific research $[9,10]$. The idea of IF was first coined by Garfield in 1955 [11]. It is an instrument for the assessment of quality of the journal monitored periodically by Thomson Scientific (formerly International Scientific Institute-ISI), Philadelphia [12]. Although, there are several criticisms regarding the usage of IF as a tool to measure the quality of publication $[13,14]$, it is still a very simple, convenient and quick indicator for assessing the impact and quality of research [15]. Furthermore, this parameter is given a lot of weightage for recruitments, funding, promotions and rewards [15].

To date, no study has documented the opinion of scientists from LDC regarding the difficulties in publishing their work. Therefore, this online survey was conducted with the primary aim of determining the opinion of corresponding authors of published papers in international Pharmacology journals regarding the perceived difficulties in publishing their findings and the possible solutions. The secondary aim of the study was to determine the number of publications emanating from LDC in Pharmacology journals.

\section{Methods}

\section{Identification and inclusion of journals}

Pubmed was accessed in the first week of June 2010. Medline journals were searched by the broad subject term "Pharmacology", while related subject terms were not taken into account. The search generated 297 titles of Pharmacology journals which were indexed by Pubmed. After a thorough scrutiny, 131 journals were included in study (Table 1). The rest were excluded due to one of the following reasons. The journal was no longer being published with the same name as was retrieved from search; this included change of name or the merger with some other journal, or the last publication was more than a year old. Non-English language journals were also excluded from the study.

\section{Data collection}

The latest issue of each of the selected 131 Pharmacology journals was reviewed thoroughly. For this, the web sites of the journals were accessed to check for the latest print issue. For online only journals, the latest issue was taken into account. The web sites of certain journals were nonfunctional; in those cases the abstracts of the latest issues were retrieved from Pubmed. The addresses of corresponding authors of original articles including short communications, and review papers were obtained. Editorials, commentaries and correspondences were excluded. The articles were selected in which the corresponding authors belonged to countries other than the high income OECD countries. At the time of designing the study (April 2010), 27 countries were mentioned as members of the
OECD on the Organisation's web site and accordingly these countries were excluded from the study. A data base was created in Microsoft word for those articles published from non-OECD countries. The data base contained abstract with full citation data, names of the authors with affiliation and e mail addresses of corresponding authors (if available). A review of the latest issues of journals was started from the last week of June 2010 and was completed in the middle of September. A separate data base was created in Microsoft Excel in which the information about the volume and issue of the journals (which were reviewed), date of publication, journal IF for 2009, total number of articles published in that particular issue, number of papers from non-OECD countries and the country of corresponding authors were entered. All the corresponding authors whose e mail addresses were available were contacted through e mail. A structured questionnaire was sent to them that contained questions asking their opinion regarding the publications from the LDC in Pharmacology journals (Appendix I). In a few instances, there was more than one paper from the same corresponding author in one issue; in that case separate e mails were sent to them for each paper. In some papers, there were more than one corresponding authors; in that case, all corresponding authors were contacted. The first response for that particular publication was entered for analysis. For nonresponders, the reminders (up to three) were sent after two weeks following the preceding e mail. Figure 1 depicts the flow of study.

\section{Statistical analysis}

All the filled questionnaires from the corresponding authors were edited, coded and the responses were entered. As per the objectives of the study, the data presented are mainly descriptive. Pearson Correlation Coefficient was used to observe the direction and strength of relationship between the journal IF and percentage of publications emanating from the LDC. A scatter plot was also made to demonstrate this relationship.

\section{Results}

As mentioned in the Methods, after exclusion, 131 Pharmacology journals were reviewed (Table 1). The total number of papers in all journals was 1919. Out of these, 584 (30.4\%) originated from the non-OECD (hereafter referred as less-developed) countries. E mail addresses of 69 corresponding authors could not be retrieved. Corresponding authors of the remaining 515 papers were sent an e mail with an attached questionnaire. E mail could not be delivered to nine authors and five authors declined to participate. At the end of the study, 332 responses (response rate; 64.5\%) were received (Figure 1). 
Table 1 Journals included in the survey

\begin{tabular}{|c|c|c|}
\hline AAPS J & Drug Discov Today & J Pharmacol Sci \\
\hline AAPS PharmSciTech & Drug Metab Dispos & J Pharm Pharm Sci \\
\hline Acta Pharmacologica Sinica & Drug Metab Pharmacokinet & J Physiol Pharmacol \\
\hline Adv Drug Delivery Rev & Drug Metab Lett & J Vet Pharmacol Ther \\
\hline Adv Pharmacol & Drug Metab Rev & Magnes Res \\
\hline Aliment Pharmacol Ther & Drug News Perspect & Mar Drugs \\
\hline Ann Pharmacother & Drug Test Anal & Med Res Rev \\
\hline Arzneimittel-Forschung & Drugs & Methods Find Exp Clin Pharmacol \\
\hline Assay Drug Dev Techn & Eur J Clin Pharmacol & Mol Diagn Ther \\
\hline Auton Autacoid Pharmacol & Eur J Pharm Sci & Mol Interv \\
\hline Basic Clin Pharmacol Toxicol & Eur J Pharm Biopharm & Mol Pharm \\
\hline Behav Pharmacol & Eur J Pharmacol & Mol Pharmacol \\
\hline Biochem Pharmacol & Eur Rev Med Pharmacol Sci & Nat Prod Commun \\
\hline Biol Pharm Bull & Expert Opin Drug Deliv & Nat Rev Drug Discov \\
\hline Biopharm Drug Dispos & Expert Opin Drug Saf & Naunyn-Schmiedeberg's Arch Pharmacol \\
\hline Brit J Clin Pharmacol & Expert Opin Pharmacother & Neuropharmacology \\
\hline Brit J Pharmacol & Expert Rev Pharmacoeconomics Out Res & Pak J Pharm Sci \\
\hline Can J Physiol Pharmacol & Food Drug Law J & PDA J Pharm Sci Technol \\
\hline Cardiovasc Hematol Agents Med Chem & Fund Clin Pharmacol & Pharm Dev Technol \\
\hline Cell Physiol Biochem & IDrugs & Pharm Res \\
\hline Cent Nerv Syst Agents Med Chem & Immunopharmacol Immunotoxicol & Pharm Stat \\
\hline Chem Pharm Bull & Indian J Physiol Pharmacol & PharmacoEconomics \\
\hline Chem Biol Drug Des & Inflammopharmacology & Pharmacogenet Genomics \\
\hline Chem-Biol Interact & Int Immunopharmacol & Pharmacogenomics \\
\hline ChemMedChem & Int J Clin Pharmacol Ther & Pharmacogenomics J \\
\hline Clin Drug Invest & Int J Immunopathol Pharmacol & Pharmacol Rep \\
\hline Clin Exp Pharmacol Physiol & Int J Pharm & Pharmacol Research \\
\hline Clin Pharmacokinet & Invest New Drugs & Pharmacol Reviews \\
\hline Clin Pharmacol Ther & J Basic Clin Physiol Pharmacol & Pharmacology \\
\hline CNS Drugs & J Biopharm Stat & Pharmacol Ther \\
\hline Comp Biochem Physiol C & J Cardiovasc Pharmacol & Pharmacol Biochem Behav \\
\hline Curr Clin Pharmacol & J Cardiovasc Pharmacol Ther & Proc West Pharmacol Soc \\
\hline Curr Comput Aided Drug Des & J Clin Pharmacol & Prog Drug Res \\
\hline Curr Drug Deliv & J Control Release & Prog Med Chem \\
\hline Curr Drug Discov Technol & J Drug Target & Pulm Pharmacol Ther \\
\hline Curr Drug Saf & J Ethnopharmacol & Recent Pat Drug Deliv Formul \\
\hline Curr Mol Pharmacol & J Nat Prod & Recent Pat Inflamm Allergy Drug Discov \\
\hline Curr Opin Drug Discov Dev & J Neuroimmune Pharmacol & Regul Toxicol Pharmacol \\
\hline Curr Opin Pharmacol & J Ocul Pharmacol Ther & Skin Pharmacol Physiol \\
\hline Curr Pharm Biotechnol & J Pharm Biomed Anal & Toxicol Appl Pharmacol \\
\hline Curr Pharm Des & J Pharm Pharmacol & Trends Pharmacol Sci \\
\hline Curr Vasc Pharmacol & J Pharm Sci & Value Health \\
\hline Drug Deliv & J Pharmacol Exp Ther & Vasc Pharmacol \\
\hline Drug Des Dev Ther & J Pharmacol Toxicol Methods & \\
\hline
\end{tabular}

The titles of the journals were retrieved from Pubmed using key word "Pharmacology". After exclusion as mentioned in "Methods", all journals mentioned in the Table were analyzed in the study. 


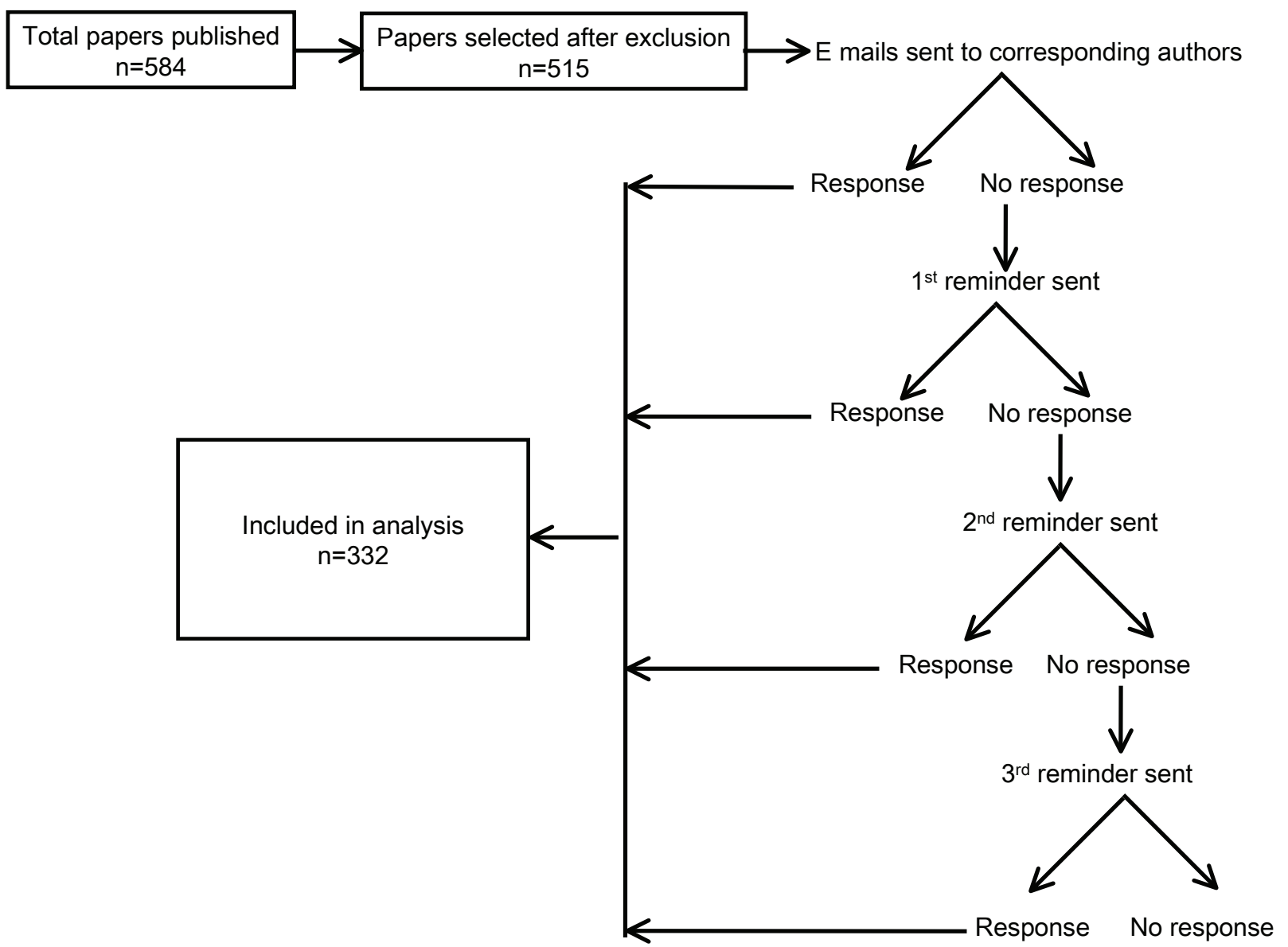

Figure 1 Flow chart of the study.

The characteristics of the papers published in Pharmacology journals and those of the authors are presented in Table 2. Approximately half of the papers from LDC were published in journals with an IF of less than 2. Only 7.0\% of all the papers were published in journals with an IF of more than 4. As mentioned by the corresponding authors, $47.9 \%$ of those publications had been rejected previously by other journals. The average number of times, the currently published papers were earlier rejected was 1.57 (range; $0-4$ ). Nearly $8 \%$ of the publications contained at least one coauthor from countries belonging to OECD. An overwhelming majority of the corresponding authors were faculty $(86.2 \%)$ followed by students (6.6\%).

The journal IF for year 2009 was noted. Figure 2 illustrates the correlation between the journal IF and the publication rate from the LDC. A weak negative correlation $(r=-0.236)$ was observed between the journal IF and the percentage of publications emanating from LDC. This indicates that as the IF of the journal increases the percentage of publications from LDC decreases.

Table 3 shows the country affiliation of corresponding authors. Forty-three countries were represented in the papers published in Pharmacology journals. China had the highest number of publications $(28.6 \%)$ followed by India (19.7\%) and Brazil (6.3\%).

A significant majority of the corresponding authors $(\mathrm{n}=254 ; 76.5 \%)$ perceived that it is difficult to publish in good quality journals from their countries. These authors who perceived difficulties in publication from their countries were further asked to identify the reasons underlying the perceived difficulties in publication. 250 authors responded to this question and according to their opinion, biased attitude of editors and reviewers $(64.8 \%)$ is the most important reason, followed by poor writing skills of the scientists (52.8\%) from LDC (Table 4).

All corresponding authors were also asked to identify the factors which might enhance the chances of acceptance of papers submitted by scientists from LDC. As shown in Table 5, according to their opinion, well-written manuscript (76.1\%), improvement in the quality of research (69.9\%) and multidisciplinary research (42.9\%) are important determinants that may improve the chances for publications. 
Table 2 Characteristics of papers and their corresponding authors

\begin{tabular}{|c|c|c|c|}
\hline Characteristics & $\begin{array}{c}n(\%) \\
N=584^{*}\end{array}$ & Characteristics & $\begin{array}{c}n(\%) \\
N=332 *\end{array}$ \\
\hline Journal Impact Factor & & Paper rejected from other journal(s) & $159(47.9)$ \\
\hline$<1.00$ & $165(28.2)$ & & \\
\hline $1.00-<2.00$ & $118(20.2)$ & & \\
\hline $2.00-<3.00$ & $186(31.9)$ & & \\
\hline $3-<4$ & $73(12.5)$ & & \\
\hline$\geq 4$ & $42(7.2)$ & & \\
\hline Number of authors & & Corresponding authors & \\
\hline 1 & $12(2.1)$ & & \\
\hline $2-4$ & $242(41.4)$ & Faculty & $286(86.2)$ \\
\hline $5-7$ & $226(38.7)$ & Students & $22(6.6)$ \\
\hline 8-10 & $81(13.9)$ & Industry & $14(4.2)$ \\
\hline \multirow[t]{2}{*}{$>10$} & $23(3.9)$ & person & $10(3.0)$ \\
\hline & & Others & \\
\hline Co-author(s) from developed country & $46(7.9)$ & & \\
\hline
\end{tabular}

*The number of responses varies because the source of data as mentioned above in the Table caption is different.

The table shows the characteristics of the publications and the corresponding authors. The data on the number of authors and the presence of coauthor from developed countries was obtained from the papers themselves. The data on previous rejection(s), and position of corresponding authors were obtained from the authors themselves via e mail.

\section{Discussion}

This study has documented for the first time the representation of papers from LDC in Pharmacology journals and the opinion of the corresponding authors from these countries regarding the difficulties in publishing their studies.

The classification of the countries into developed and less-developed was based upon the membership of OECD. Those with OECD membership were labeled as developed and others as less-developed. The rationale for following this classification is that as OECD membership is restricted to high income countries as defined

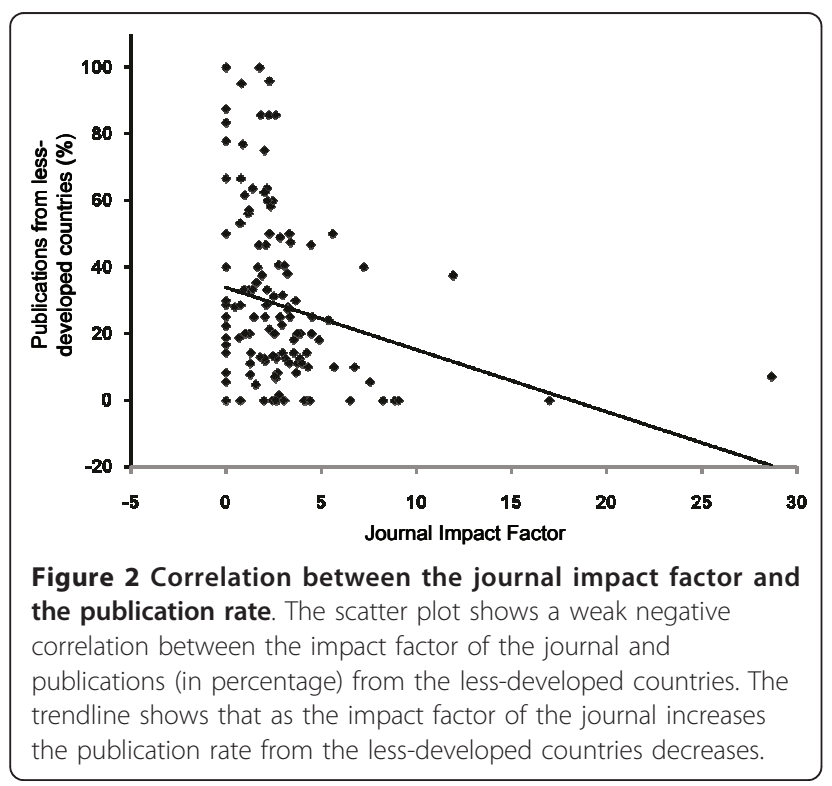

by the World Bank [16] which have an established democratic government set up [17]. However, it should be noted that at the time of the study design, the membership of OECD was only 27, which has expanded up to 34 countries at the time of writing the manuscript. The data obtained from the authors of 7 new OECD members is included with other LDC.

According to US Census Bureau's International Data Base, OECD countries comprise only $13 \%$ of the world population in the year 2010 [18]. However, this part of the world contributed more than two thirds of the total number of publications in Pharmacology journals compared to around $30 \%$ by the LDC. There were four journals; one each from China, India, Pakistan and Poland which published articles mainly from their own countries.

Table 3 Major countries contributing to publications from developing countries

\begin{tabular}{cc}
\hline Country & Number of publications (\% of total) \\
\hline China & $167(28.6)$ \\
\hline India & $115(19.7)$ \\
\hline Brazil & $37(6.3)$ \\
\hline Korea & $36(6.2)$ \\
\hline Mexico & $35(6.0)$ \\
\hline Poland & $30(5.1)$ \\
\hline Iran & $20(3.4)$ \\
\hline Turkey & $15(2.6)$ \\
\hline Argentina & $14(2.4)$ \\
\hline Others (34 countries) & $115(19.7)$ \\
\hline Total & $\mathbf{5 8 4}(\mathbf{1 0 0 . 0 0 )}$
\end{tabular}


Table 4 Reasons underlying difficulties in publications in the opinion of corresponding authors

\begin{tabular}{cc}
\hline Reason & $\mathbf{n}(\mathbf{\%}$ of respondents) $\mathbf{N}=\mathbf{2 5 0}$ \\
\hline Piased attitude of reviewers and editors against authors from developing countries & $162(64.8)$ \\
\hline Poor writing skills & $132(52.8)$ \\
\hline Reviewers and Editors do not trust data generated in developing countries & $100(40.0)$ \\
\hline Quality of research is not good in developing countries & $78(31.2)$ \\
\hline Lack of funding and other resources & $74(29.6)$ \\
\hline Unimpressive publication record of the authors & $42(16.8)$ \\
\hline Lack of generalisibility of results & $18(7.2)$ \\
\hline Total responses* & $\mathbf{6 0 6}$ \\
\hline
\end{tabular}

*The number of responses (606) exceeds the number of respondents (250) because the majority of respondents selected more than one reasons. The corresponding authors who thought that publishing from their countries is difficult were asked to identify the reasons underlying the difficulties in publishing.

This somewhat inflated the representation of publications from LDC. If we exclude these four journals from the analysis, the actual representation in international journals drops to $26.7 \%$. Previously, publication rates of 4.8 [19] and 6.0\% [4] in psychiatry, 5.0\% in tropical medicine [20], 6.5\% in internal medicine [21], 5.5\% in ophthalmology [22], 0.3\% in anesthesiology [23] and very few in surgery [24] journals from LDC have been reported. These figures are grossly different from those presented in this study. However, there is a basic difference in the methodology of above studies and the current one. Previous reports have analysed only those papers that were published in leading journals with high IF in their respective fields. However, our study has analysed all Medlineindexed Pharmacology journals. Since we found that the publication rate from LDC is weakly but negatively correlated with the IF of the journal, the top ten highest ranking journals were analysed, separately. As expected, the publication rate from LDC markedly dropped to $10.2 \%$ in those journals, which approaches to already published reports. This finding is consistent with the response of corresponding authors; an overwhelming majority of

Table 5 Attributes that increase the chances of acceptance for publication in good quality journals

\begin{tabular}{|c|c|}
\hline Attribute & $\begin{array}{c}\mathrm{n} \text { (\% of respondents) } \\
\mathrm{N}=326\end{array}$ \\
\hline Well-written manuscript & $248(76.1)$ \\
\hline Improvement in the quality of research & $228(69.9)$ \\
\hline Multidisciplinary research & $140(42.9)$ \\
\hline $\begin{array}{l}\text { Having collaborator/coauthor from } \\
\text { developed country }\end{array}$ & $120(36.8)$ \\
\hline Sound publication record & $86(26.4)$ \\
\hline Total responses* & 822 \\
\hline
\end{tabular}

*The number of responses (822) exceeds the number of respondents (326) because majority of respondents selected more than one attribute. All corresponding authors from the less-developed countries were asked to identify the measures that can increases the chances of acceptance of their manuscript. whom believes that it is difficult to publish in high quality international journals.

In the face of the population size of the LDC, there is a gross underrepresentation of publications emerging from these countries. In order to understand the reasons underlying this underrepresentation, the corresponding authors were asked to identify them. Broadly, the reasons identified by them can be grouped into two categories. First, the reasons that are associated with the review process of the journals such as biased attitude and lack of trust among reviewers and editors on the data generated in their countries. In the second category, the reasons are associated with deficiencies prevailing within the scientists from LDC such as poor writing skills and poor quality of research. The former reasons were identified as the major hurdles underlying the non-acceptance of their publications by an overwhelming majority of authors. Indeed, there are some reports that have suggested that the data generated in low income nations is undervalued [25]. Moreover, a statistically significant difference between the high and low income countries in terms of rejection rate of submitted manuscripts has been shown [26].

As far as the improvement in the quality of research in LDC is concerned, this is mainly linked to the political system of the country. It is known that research is the last priority in the majority of LDC with science being considered by governments as a luxury that can be afforded only by rich countries [27]. Thus poor funding, lack of incentives to scientists and resources will eventually lead to poor research facilities, limited technical support and inadequate training. Obviously, with all these barriers, the scientific activities and research will be hampered. It is conceivable that under these lessencouraging circumstances, both quantity and quality of research would also be affected. Indeed, it has been shown that the number of submissions from LDC was far fewer (5.2\% of the total submissions) compared to high income countries in psychiatry journals [19]. As far as the other reasons identified by the authors are concerned, 
if these are valid, they can easily be resolved by the scientific community and the international journals. For example, one inherent reason is the poor writing skills of researchers from LDC because English is not the first language for the majority of these nations. Influential international journals with adequate human resources can come forward and offer a free service for checking and editing the manuscripts from non-English speaking scientists once they are accepted for publication. As a matter of policy, rejection of papers based on the inadequate usage of language should not be acceptable. International journals can initiate another measure to bridge this gap between the developed countries and LDC by reserving some pages for papers from LDC. This reserved section should publish the best research emanating from the LDC only. This would have a positive impact on the enthusiasm of the scientists. One case can be cited to reinforce this suggestion. The Journal of Pakistan Medical Association started a reserved section for students in 2004. This fostered an interest towards research among undergraduate medical students and student research groups at regional and national levels were made. Publications of their results as lead authors motivated them to involve themselves in larger projects. Recently, the undergraduate medical students have launched their own journal. Furthermore, notable scientists from the LDC should be invited to serve on the editorial staff of the international journals since presently, the majority of editorial board members of international medical journals are residents of highly developed nations $[20,28]$. This step may help eliminate the feeling among authors from LDC that their findings are not given importance.

One limitation of the study is that the data was generated from papers published in only one issue of all Pharmacology journals. It is likely that these data may not be representative of the overall situation. However, the inclusion of all the journals in the current study has yielded a sample size which may be considered as sufficiently representative. Second limitation of the current study is that division of countries is based on the membership of OECD. This has put some high income countries like oil-rich Gulf States into LDC. However, this has been done purposefully because the academic history of these countries is rather brief. The third limitation is that Pharmacology related subject terms like antibacterial drugs, toxicology etc were not taken into account resulting in many journals that were not included.

\section{Conclusions}

The LDC are underrepresented in publications in Pharmacology journals. The corresponding authors of the published articles perceive that biased attitude of the editors as well as the reviewers of international journals and the poor writing skills of scientists are the major factors underlying the non-acceptance of their scientific work. They also think that the improvement in the writing skills and quality of research will increase the chances of acceptance of their works in international journals.

\section{Appendix I}

Q1. You are a

$\square$ Faculty

$\square$ Industry person

$\square$ Trainee

$\square$ Support staff

$\square$ Student

$\square$ Any other (please specify)

Q2. Did you submit the present paper in some other journal(s) where it was rejected?

$\square$ Yes

$\square$ No

Q3. How many journals?

$\square 1$

$\square 2$

$\square 3$

$\square 4$

$\square$ More than 4

Q4. How long did it take from drafting of manuscript to final acceptance (including all the previous rejections if any)? (months)

Q5. Do you think that it is difficult to publish papers from your country in journals of high impact factors?

$\square$ Yes

$\square$ No

Q6. If your answer to question 5 is yes than what do you think might be the reason(s) (you can choose more than one option)?

$\square$ Quality of research is not good

$\square$ Biased attitude of editors and reviewers towards researchers from developing countries

$\square$ Writing skills of scientists from developing countries are not good

$\square$ Editors \& reviewers do not trust data from developing countries

$\square$ Lack of generalisibility of results from developing countries

$\square$ Unimpressive publication record of the authors

$\square$ Lack of funding to cover publication costs in some journals

$\square$ Any other (please specify)

Q7. What in your opinion will increase the chances of acceptance in journals of high impact factors (you can choose more than one option)?

$\square$ Improvement in the quality of research

$\square$ Well written manuscript

$\square$ Multidisciplinary research 
$\square$ Having co-author from developed country

$\square$ Sound publication record of first or corresponding author

$\square$ Any other (please specify)

\begin{abstract}
Acknowledgements
I acknowledge Mr. Iqbal Azam from the Department of Community Health Sciences, Aga Khan University, who helped me in the statistical analysis of data presented in this paper. I am also thankful to my colleagues Professors Ronald D. Meersman and Juurlink Bernhard for critically reviewing the manuscript and refining it.
\end{abstract}

\section{Competing interests}

The author declares that they have no competing interests.

Received: 31 December 2010 Accepted: 5 May 2011

Published: 5 May 2011

\section{References}

1. Grieger MCA: Authorship: an Ethical Dilemma of Science. Sao Paulo Med J 2005, 123:242-246.

2. Nederhof AJ: Policy impact of bibliometric rankings of research performance of departments and individuals in economics. Scientometrics 2008, 74:163-174.

3. Yach D, Kenya P: Assessment of epidemiological and HIV/AIDS publications in Africa. Int J Epidemiol 1992, 21:557-560.

4. Patel V, Sumathipala A: International representation in psychiatric literature: survey of six leading journals. Br J Psychiatry 2001, 178:406-409.

5. Mendis S, Yach D, Bengoa R, Narvaez D, Zhang X: Research gap in cardiovascular disease in developing countries. Lancet 2003, 361:2246-2247.

6. Horton R: North and South: bridging the information gap. Lancet 2000, 355:2231-2236.

7. Garfield E: Citation indexing for studying science. Nature 1970 227:669-671.

8. Garfield E: Citation analysis as a tool in journal evaluation. Science 1972, 178:471-479.

9. Taubes G: Measure for measure in science. Science 1993, 260:884-886.

10. Calza L, Garbisa S: Italian professorships. Nature 1995, 374:492.

11. Garfield E: Citation indexes to science: a new dimension in documentation through association of ideas. Science 1955, 122:108-111.

12. Garfield E: The history and meaning of the journal impact factors. JAMA 2006, 295:90-93.

13. Seglen PO: Why the impact factor of journals should not be used for evaluating research. BMJ 1997, 314:498-502.

14. Colquhoun D: Challenging the tyranny of impact factors. Nature 2003, 423:479.

15. Glanzel W, Moed HF: Journal impact measures in bibliometric research. Scientometrics 2002, 53:171-193.

16. The World Bank. [http://data.worldbank.org/about/country-classifications], (accessed on April 2010)

17. The organization for Economic Co-operation and development. [http:// www.oecd.org/pages/0,3417,en_36734052_36734103_1_1_1_1_1,00.html], (accessed on April 2010).

18. US Census Bureau, International Data Base (IDB). [http://www.census.gov/ ipc/www/idb/index.php], (accessed on December 2010).

19. Singh D: Publication bias- a reason for the decreased research output in developing countries. S Afr Psychiatry Rev 2006, 9:153-155.

20. Keiser J, Utzinger J, Tanner M, Singer BH: Representation of authors and editors from countries with different human development indexes in the leading literature on tropical medicine: survey of current evidence. BMJ 2004, 328(7450):1229-1232.

21. Sumathipala A, Siribaddana S, Vikram P: Under-representation of developing countries in the research literature: ethical issues arising from a survey of five leading medical journals. BMC Med Ethics 2004, 5:5.

22. Mandal K, Benson S, Fraser SG: The contribution to ophthalmic literature from different regions of the world. Int Ophthalmol 2004, 25(3):181-184.
23. Bould MD, Boet S, Riem N, Kasanda C, Sossou A, Bruppacher HR: National representation in the anaesthesia literature: a bibliometric analysis of highly cited anaesthesia journals. Anaesthesia 2010, 65(8):799-804.

24. Mahawar KK, Malviya A, Kumar G: Who publishes in leading general surgical journals? The divide between the developed and developing worlds. Asian J Surg 2006, 29(3):140-144.

25. Yousefi-Nooraie R, Shakiba B, Mortaz-Hejri S: Country development and manuscript selection bias: a review of published studies. BMC Med Res Methodol 2006, 6:37.

26. Patel V, Youl-ri K: Contribution of low- and middle-income countries to research published in leading general psychiatry journals, 2002-2004. Br J Psychiatry 2007, 190:77-78.

27. Alem A: Conducting psychiatric research in the developing world: challenges and rewards. Br J Psychiatry 2003, 182:185-187.

28. Tutarel O: Composition of the editorial boards of leading medical education journals. BMC Med Res Methodol 2004, 4:3.

Pre-publication history

The pre-publication history for this paper can be accessed here: http://www.biomedcentral.com/1471-2288/11/60/prepub

doi:10.1186/1471-2288-11-60

Cite this article as: Rohra: Representation of less-developed countries in Pharmacology journals: an online survey of corresponding authors. BMC Medical Research Methodology 2011 11:60.

\section{Submit your next manuscript to BioMed Central and take full advantage of:}

- Convenient online submission

- Thorough peer review

- No space constraints or color figure charges

- Immediate publication on acceptance

- Inclusion in PubMed, CAS, Scopus and Google Scholar

- Research which is freely available for redistribution 